\title{
Uranium circuit development for a West African polymetallic deposit
}

\author{
by A.J. du Toit, and S.J. Archer
}

\section{Synopsis}

This article presents the process flow sheet development conducted in 2013 on a polymetallic deposit located in West Africa. The mineralization, consisting of uranium and to a lesser extent silver and copper, posed challenges due to the presence of high levels of both carbonates (acid consumers) and sulphides (alkali consumers). It was established that copper and silver were associated with the sulphides and could be separated by means of flotation. Thus a trade-off study was conducted to evaluate both alkali and acid processing routes for the recovery of uranium. The following two flow sheets were investigated:

1. Acid leaching of the run-of-mine (ROM) ore, followed by sulphide flotation of leach tails for the recovery of silver and copper from the concentrate

2. Sulphide flotation of the ROM ore for silver and copper recovery, followed by alkali leaching of the float tails for uranium recovery.

The trade-off study showed a differential operating cost saving of between $10 \%$ and $40 \%$, within a $90 \%$ confidence level, in favour of the alkali-based flow sheet, which was selected for further evaluation and optimization.

Further flow sheet development was also conducted to determine the following:

> Alkali addition and minimizing water requirements

> Processing of flotation concentrates to produce saleable silver and copper by products.

Keywords

uranium, process development, polymetallic ore, alkali leaching, acid leaching. consists mainly of quartz, muscovite, chlorites, carbonates, and feldspars.

A six-week process concept study was initially executed during the second quarter of 2011. An atmospheric acid leach flow sheet was selected as the basis for the concept study, and comprised the following unit operations:

$>$ Ore receiving

$>$ Crushing

Ball milling

> Primary atmospheric acid leach

- Resin-in-pulp (RIP)

- Froth flotation

> Solvent extraction (SX)

> Sodium diuranate (SDU) precipitation

> Drying and packaging

$>$ Consideration of the potential sale of the flotation concentrate (not included in the concept study operating cost (OPEX) estimate).

Following the completion of the concept study, it was concluded that the high sulphuric acid consumption in the atmospheric leach circuit had a dramatic effect on the plant OPEX and subsequently affected the overall project economics negatively. The abnormally high acid consumption ranged from $65 \mathrm{~kg} / \mathrm{t}$ to $100 \mathrm{~kg} / \mathrm{t}$ ROM material. Typical North American operations consume $18 \mathrm{~kg}$ to $50 \mathrm{~kg}$ sulphuric acid per ton of ore (Merrit, 1971). The high acid consumption was attributed to the carbonate content of the ore. Uranium leach extractions of $85 \%$ to $88 \%$ were initially observed. Scoping an alkali leaching route of the ore resulted in high reagent (carbonate) consumption rates, but at significantly higher uranium leach extractions $(90.5 \%$ to $91.6 \%$.) The high carbonate consumption for the scoping alkali tests was ascribed to the sulphide content of the ore.

* DRA Projects, South Africa.

(C) The Southern African Institute of Mining and Metallurgy, 2018. ISSN 2225-6253. This paper was first presented at the Uranium 2017 International Conference, 12-13 September 2017, Swakopmund Hotel, Swakopmund, Namibia.. 


\section{Uranium circuit development for a West African polymetallic deposit}

Golder Associates Inc. conducted a feasibility assessment on the potential for in situ recovery (ISR) of uranium. It was determined that the host formation did not have sufficient permeability to enable lixiviant to percolate through the ore zone. The International Atomic Energy Agency (IAEA), in its technical document on acid leaching of uranium ores, defines hydraulic permeability below $1 \mathrm{~m} / \mathrm{d}$ as very low and unfavourable for uranium recovery by the ISR process (IAEA, 2001). The test results indicated permeability of several orders of magnitude below this limit, which confirmed that the ISR method was not feasible for this orebody.

Various comminution test work evaluations were conducted. Bond rod mill and Bond ball mill work indices (BRWi and BBWi) were used to calculate comminution energy requirements based on various top sizes. BRWi, when compared to BBWi, indicated a relative degree of ore competency. The JK drop weight test was used to determine rock breakage parameters. Parameters derived from the test work, together with operating parameters, were used to predict autogenous or semi-autogenous milling behaviour, and to confirm crushing and milling parameters employed in the comminution circuit design. The results indicated that the deposit material could be characterized as medium to moderately hard. The unconfined compressive strength values for various samples evaluated ranged widely (60 MPa to $140 \mathrm{MPa}$ ) but were generally high, also indicating competent ore.

The presence of native silver nuggets was identified during the flotation piloting test work. Variability was observed in the silver deportment, analyses, and reported recoveries. However, mineralogical analyses showed that all floatable silver species were recovered, notwithstanding the analytical variability due to the presence of the silver nuggets. Furthermore, it was determined that gravity concentration would not be a viable option for separating and upgrading the silver nuggets after milling. The flotation test work on milled ore $\left(P_{80}\right.$ of $\left.75 \mu \mathrm{m}\right)$ resulted in typical copper and silver recoveries of between $90 \%$ and $92 \%$ into mass pulls of approximately $3.5 \%$ to $6.3 \%$.

Although crushing, milling, and flotation observations have been provided above as background information, the main focus of the article will be on the following items:

> Acid versus alkali process route trade-off

$>$ Alkali circuit configuration trade-off:

- Leach/RIP

- Leach/countercurrent decantation (CCD)/ion exchange (IX)

- Leach/CCD/evaporation or membrane technology

- Leach/filtration/evaporation or membrane technology

- Leach/RIP/CCD

- Optimization of the CCD circuit

> Flotation concentrate processing issues and options:

- Radionuclide removal from concentrate

- Uranium, copper, and silver recovery from sulphide concentrate:

- Uranium recycled to alkali circuit

- Ag-jarosite formation:

- Lime boil application

- Sulphur flotation.

A 2013 financial base date was used for all the financial data used and reported in this article.

\section{Acid versus alkali process route trade-off}

Broadly, two leaching strategies exist for uranium extraction: sulphuric acid leaching or carbonate (alkali) leaching. An alkali leach is generally more selective than acid leaching and is particularly useful for high-lime and carbonate-containing ore that would consume excessive amounts of acid (Merrit, 1971). The ore from the deposit contains high levels of carbonate (acid consumers), as well as sulphides (alkali consumers). It is possible to separate sulphides from other mineral phases using froth flotation, which could result in a substantial reduction in the overall operating costs. As a result, two flow sheet options were identified for the recovery of uranium and secondary products from the milled ore:

> Acid leaching of ROM ore for uranium recovery, followed by flotation of the leach tailings and recovery of silver and copper from the flotation concentrate

> Flotation of ROM ore for silver and copper (sulphide) recovery, followed by alkali leaching of the flotation tailings for uranium recovery. This option follows a similar processing theme as the Canadian Beaverlodge operation (Feasby, 1980).

Prior to commencing with the internal economic study, the DRA process team was requested to undertake a highlevel desktop trade-off evaluation, with the objective of assessing whether either of the two processing options could provide a significant operating cost saving, and could be selected for further investigations or test work. The selection of one option on this basis would simplify the test work requirements, engineering focus, and subsequent cost and timing for completion of the internal economic study.

From the alkali/acid trade-off study there appeared to be enough motivation, despite the levels of test work and engineering completed at the time, to proceed with the second option (the alkali-based flow sheet).

The trade-off methodology that was applied included the following:

> Development of a concept techno-financial model (based on limited engineering and test data available at the time)

> Use of 2013 reagent and transport costs

- Following a stochastic modelling approach

> Considering only differential incremental OPEX values

> Assuming the capital cost (CAPEX) differential to be insignificant relative to the larger project capital layout

- Excluding common areas, as well as the concentrate processing area.

Block flow diagrams of the two processing options are shown in Figure 1. The trade-off study did not consider secondary metal (silver and copper) recovery, since this is common to both flow sheet options and would not necessarily impact on the acid or alkali circuit selection.

Since the focus of the trade-off was on establishing operating cost differentials, no definitive cash flow evaluations were conducted for either option. CAPEX differentials were not considered at this stage, as the differential CAPEX is expected to be small in comparison to the larger project capital.

Due to the process variability and subsequent uncertainty in reagent consumption rates, supply costs, and status of process engineering (preliminary mass and energy balances), 


\section{Uranium circuit development for a West African polymetallic deposit}

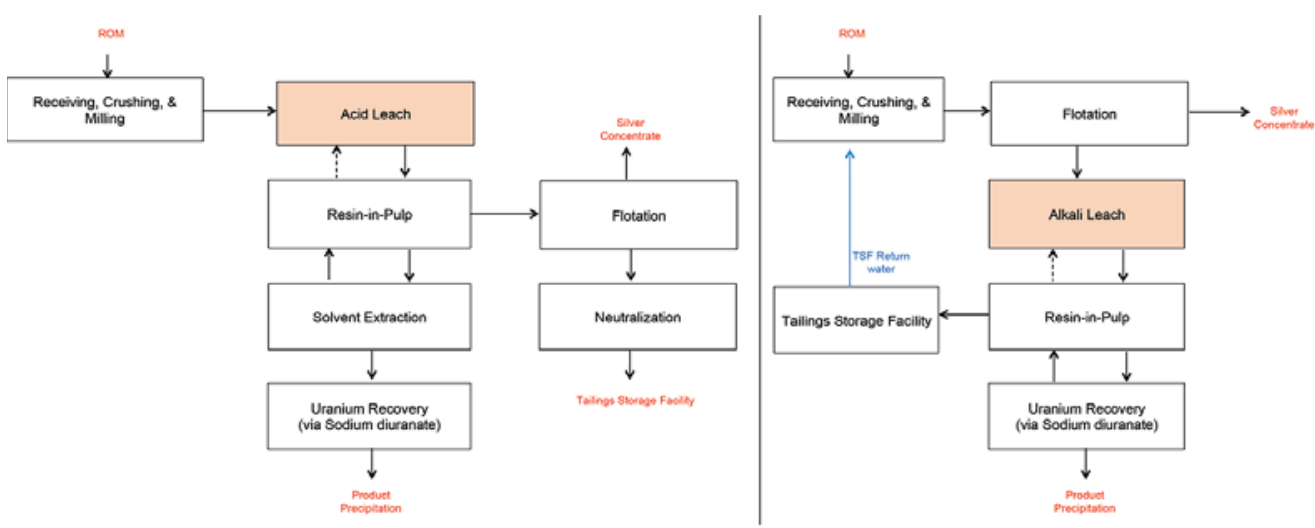

Figure 1-Block flow diagrams: acid versus alkali process options

a stochastic approach was used to assess the differential in operating costs between the two processing routes. This was done by using the Monte Carlo simulation technique, which seeks to assess the collective risk of all parameter uncertainties simultaneously, rather than using a singlevariable sensitivity analysis approach.

In the simulation, the key uncertain operating cost drivers were represented using ranges of possible values, or probability distributions, derived from metallurgical test work, preliminary high-level mass and energy balances, as well as engineering experience. This provided a framework for risk analysis, quantification, and the testing of alternatives. The Monte Carlo simulation output probability distribution, shown in Figure 2, indicates the potential operating cost saving should an alkali leach flow sheet be adopted. Based on the assumptions and preliminary test work results, the likely saving is expected to be between $10 \%$ and $40 \%$ (90\% confidence level) compared to an equivalent acid leach flow sheet. The alkali-based flow sheet was, therefore, selected for further study.

\section{Alkali circuit configuration trade-off}

One of the major uncertainty risk items identified for the alkali-based circuit was the effect of overall plant solution and salt balance, taking into account the climatic conditions (rainfall). An alkali circuit configuration review was required to optimize the use of reagents and maximize the possible recycling of unreacted reagents. Therefore, an alkali circuit configuration trade-off study was initiated based on engineering experience, and also considering various key process drivers (Lunt et al., 2007). The following five configurations were evaluated:

$>$ Leach - RIP

> Leach - countercurrent decantation (CCD) - ion exchange (IX)

> Leach - CCD - evaporation/reverse osmosis (RO)

> Leach - filtration - evaporation/RO

$>$ Leach - RIP - CCD.

The alkali circuit configuration trade-off was based on the following:

> Optimizing the solution and salt balances

- Excluding the CAPEX from the analysis

- Using high-level mass balances and test work assumptions

> Reagent/alkali requirements.

The overall alkali requirements and technology status dictated the final configuration selection. The results are shown in Table I.

A leach-CCD-IX configuration was selected as natural evaporation is not feasible in the high-rainfall areas of the West African region, and forced evaporation will be too cost-

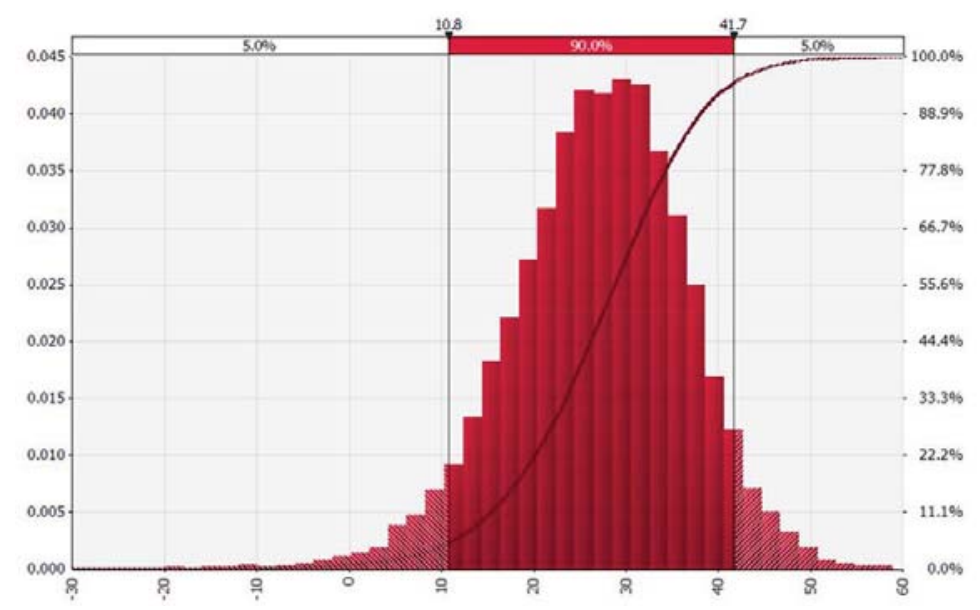

Figure 2-Acid-alkali trade-off: differential OPEX (alkali leach OPEX saving relative to acid leach) 


\section{Uranium circuit development for a West African polymetallic deposit}

Table I

Alkali configuration trade-off evaluation

\begin{tabular}{|l|c|c|c|}
\hline Circuit configuration & Alkali requirements & Technology status \\
\hline Leach-RIP & Baseline & Proven \\
Leach-CCD-IX & $40 \%$ to $80 \%$ reduction & Proven & No \\
Leach-CCD-evaporation/RO & $>80 \%$ reduction & RO not proven \\
Leach-filter-evaporation/RO & $>80 \%$ reduction & RO not proven \\
Leach-RIP-CCD & $40 \%$ to $80 \%$ reduction & Proven & No \\
\hline
\end{tabular}

intensive. RO can be incorporated in an alkali circuit for upgrading uranium, although it is not proven on a commercial scale. Another African uranium producer is currently piloting the concept of using membrane technology for reagent recovery (Peacock et al., 2016). The CCD-IX configuration was selected in preference to the RIP-CCD configuration as the IX step provides the flexibility to be replaced by RO.

\section{Optimization of the CCD circuit}

The post-alkali leach slurry is washed, while solid-liquid separation is facilitated, using a two-phase CCD system. The first phase uses barren solution from the previous IX unit operation to wash the uranium; and the second phase involves two stages of washing to balance the salts in the circuit by using fresh water as the washing solution. Initially, a high washing efficiency (approx. 99.8\%) was targeted for the uranium washing and a seven-stage system was incorporated in the design circuit, resulting in a calculated underflow uranium content of approximately 3-6 ppm $\mathrm{U}_{3} \mathrm{O}_{8}$. Subsequently, it was identified that the tailings treatment facility will incorporate a lining, and a high-level economic evaluation was conducted to determine the economical cutoff between uranium recovery and number of CCD stages. The overall washing efficiencies are shown in Figure 3.

The results of the economic evaluation are shown in Figure 4 and, based on the expected life-of-mine, it was identified that five stages of uranium washing will be sufficient for an economically viable solution.

\section{Flotation concentrate processing issues and options}

It was identified during the initial concept study that the sale of the valuable metals in the concentrate as a secondary product would play a pivotal role in the economic evaluation of the project. Flotation test work and piloting showed that the concentrate contained radioactive components. Subsequently, radionuclide removal and concentrate processing test work ensued to determine the most valueadding processing option.

\section{Radionuclide removal from concentrate}

Generally, a radioactivity level of less than $1 \mathrm{~Bq} / \mathrm{g}$ is required for a non-radioactive transport and trade agreement. The concentrate, prior to uranium removal, is in secular equilibrium as was observed by similar activities of radionuclides in each decay chain. The secular equilibrium was distributed by sulphuric acid leaching. This removed uranium as well as thorium successfully; however, radium, lead, polonium, and protactinium remained. Further radionuclide removal options were evaluated at the following batch leach conditions:

$>1 \mathrm{M} \mathrm{HCl}$ with 6 hours' residence time at $60^{\circ} \mathrm{C}$ and a solids content of $20 \% \mathrm{w} / \mathrm{w}$

> Acidified $\mathrm{NaCl}(2 \mathrm{M} \mathrm{NaCl})$ in $10 \mathrm{~g} / \mathrm{L} \mathrm{HCl}$ with 6 hours' residence time at $60^{\circ} \mathrm{C}$ and a solids content of $20 \% \mathrm{w} / \mathrm{w}$

$>1 \mathrm{M} \mathrm{HCl}$ with 6 hours' residence time at $6^{\circ} \mathrm{C}$ and a solids content of $20 \% \mathrm{w} / \mathrm{w}$, together with a complexing agent (such as EDTA).

The $\mathrm{HCl}$ leaches resulted in some components still exceeding the $2 \mathrm{~Bq} / \mathrm{g}$ activity. Subsequent thermal treatment ( 2 hours at $750^{\circ} \mathrm{C}$ under negative atmosphere) was able to reduce most of the radionuclides. However, this technique

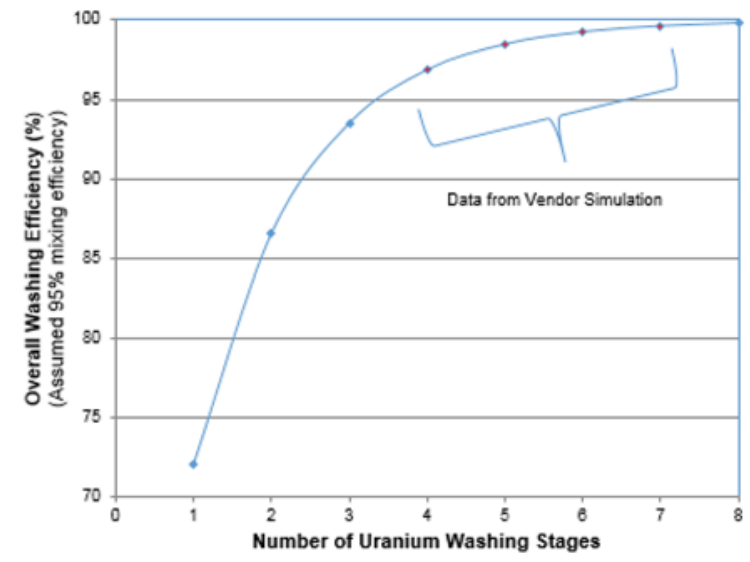

Figure 3-Washing efficiencies per number of uranium wash stages (mixing efficiency of $95 \%$ )

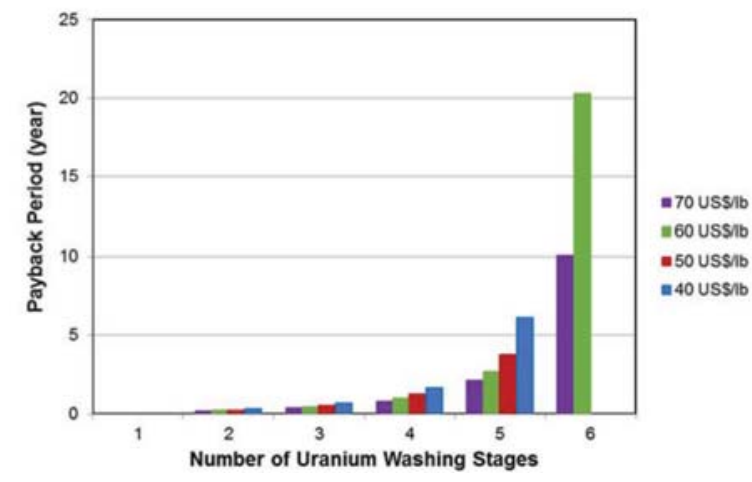

Figure 4-Payback period for each additional CCD washing stage shown for various uranium prices 


\section{Uranium circuit development for a West African polymetallic deposit}

was unable to reduce the polonium activity below a level of $2 \mathrm{~Bq} / \mathrm{g}$. The polonium activity remained at or above $2 \mathrm{~Bq} / \mathrm{g}$ regardless of the initial value. Although this corresponds to the removal of a significant portion of the polonium, the level still exceeded the $1 \mathrm{~Bq} / \mathrm{g}$ target.

After leaching to remove uranium, the copper/silver concentrate would still be classified as radioactive and would, therefore, almost certainly require processing to remove radionuclides in order to be saleable as a non-radioactive material. Although there is an opportunity to sell the partially cleaned flotation concentrate, based on the test results, the decision was taken to pursue the production of a final metal by-product.

\section{Uranium, copper, and silver recovery from sulphide concentrate}

The recovery of silver from the flotation concentrate proved to be more challenging than initially anticipated. Although some of the uranium phases are associated with sulphide minerals, it was observed that the uranium deportment followed the mass distribution. Since the silver/copper flotation concentrate also contains approximately $20 \%$ of the feed uranium, it is necessary to acid leach the concentrate to recover this uranium. The pregnant solution containing the copper and uranium will be processed for copper recovery and the uranium will be precipitated as a magnesium diuranate and recycled to the alkali leach circuit.

During the atmospheric acid leach of the concentrate, it was observed that a silver jarosite species $\left(\mathrm{AgFe}_{3}\left(\mathrm{SO}_{4}\right)_{2}(\mathrm{OH})_{6}\right)$ formed, which was not amenable to cyanide leaching. Subsequently, five processing options were identified for laboratory evaluation at ANSTO Minerals. However, test work ensued only with the first three options as they were deemed the most likely to succeed. The last two options were not evaluated due to the hazardous nature associated with the practical operability of the processes, as well as the remote location of the deposit. The options identified included the following:

> Pressure oxidative (POX) leaching, with or without lime boils, followed by cyanide leaching

> Oxidative atmospheric leaching, with or without lime boils, possible sulphur flotation, followed by cyanide leaching

> Concentrate roasting, weak acid leaching, neutralization, followed by cyanide leaching

> Chloride oxidative leach, silver cementation, and copper recovery

> Ammonia oxidative leach, followed by copper/silver precipitation.

Although it was aimed to thermally decompose the argento-jarosite species at a high temperature, (Frost et al., 2005), the initial concentrate roast option did not yield good silver recoveries. It was suspected that additional refractory silver species formed under the high-temperature roasting conditions. Technical solutions (the first two process options identified) were found to recover the silver successfully; however, when a silver-jarosite species formed, aggressive conditions were required for its destruction. Both uranium and copper can be readily leached, with high extractions (> 95\%), under the following oxidative acid leach conditions (both atmospheric and pressure):
> Atmospheric conditions: $80^{\circ} \mathrm{C}$ to $90^{\circ} \mathrm{C}, 12$ to 24 hours and an oxidative-reductive potential of approximately $450 \mathrm{mV}$ (Ag/AgCl)

> POx conditions: $180^{\circ} \mathrm{C}$ to $220^{\circ} \mathrm{C}$ with a 2- to 6-hour residence time.

Some silver was partially oxidized to a refractory form (almost certainly argento-jarosite) under atmospheric oxidative leaching conditions. The subsequent cyanide leach efficiency can be improved using an alkali pretreatment technique (e.g. lime boil) (Kasani et al., 2008). However, significant amounts of alkali reagent would be required for high silver recoveries. It was observed that sulphides oxidized to elemental sulphur during low/ambient temperature atmospheric leaches. It is likely that the elemental sulphur would consume lime during the lime boil stage, producing calcium polysulphides. Standard lime boil tests were conducted at $90^{\circ} \mathrm{C}$, at a pH of 9.5 to 10.5 , for residence times from 6 hours. The standard lime boil tests resulted in high silver extraction during cyanide leaching (approx. 97\%), but the lime consumptions were high, rendering the option economically unfeasible. Lime boils were conducted in a high-shear multiple impeller system to simulate an attrition effect and showed lower lime consumption with good subsequent silver recoveries, but were significantly more energy-intensive. It was observed that the target lime boil pH can vary, thereby varying the subsequent silver recovery and affecting the total reagent consumption.

Leach residues from the test work were sent for further flotation tests in an attempt to float residual elemental sulphur prior to lime boiling and cyanide leaching. Unfortunately, approximately $24 \%$ of the silver reported to the concentrate stream, while a substantial amount of sulphur still reported to the flotation tails and rendered the sulphur flotation option to reduce lime boil reagent consumption unsuccessful.

The addition of sodium compounds to the hightemperature oxidative leaches was found to improve the subsequent silver leach extraction due to the preferential formation of sodium jarosites. A high-level techno-financial model indicated that a cyanide leach silver recovery of $75 \%$ to $85 \%$ should be targeted, as higher recoveries were valuedestructive (see Figure 5). Figure 6 shows the increase in the overall OPEX as higher silver recoveries are targeted.

Both oxidative atmospheric and POx leaching yielded similar recoveries. However, POx was not considered for further evaluation due to the operational complexity of the process. Therefore, an oxidative atmospheric leach process was selected for processing the ore flotation concentrate. A process block flow diagram is shown in Figure 7.

\section{Conclusions and recommendation}

It was found that a sulphide flotation circuit, followed by alkali leaching of the flotation tails, will provide the best value for this deposit. Furthermore, owing to the low uranium price, recovery of copper and silver by-products was targeted to provide by-product credits to make the financial case more attractive. However, difficulties were encountered with the silver flotation due to the presence of native silver nuggets, and a refractory silver species was formed during acidic leaching of the concentrate that rendered the silver not 


\section{Uranium circuit development for a West African polymetallic deposit}

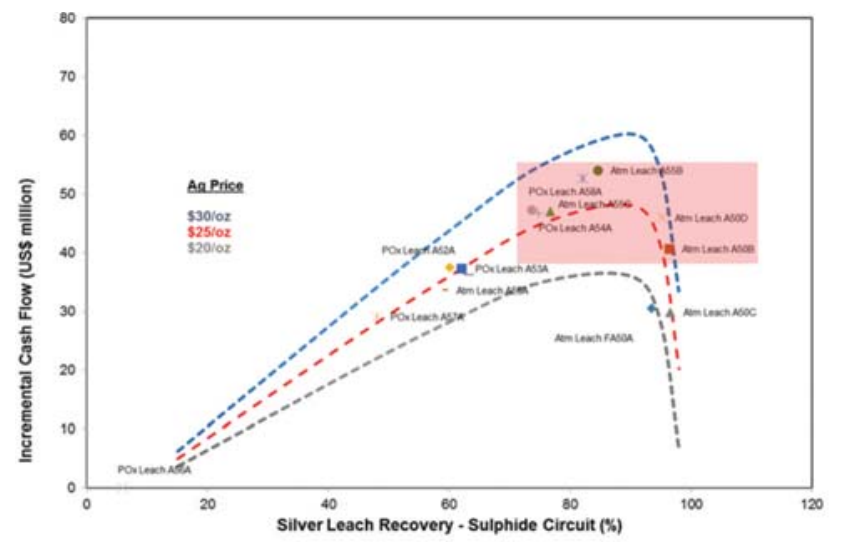

Figure 5-Potential value addition as function of targeted silver recovery

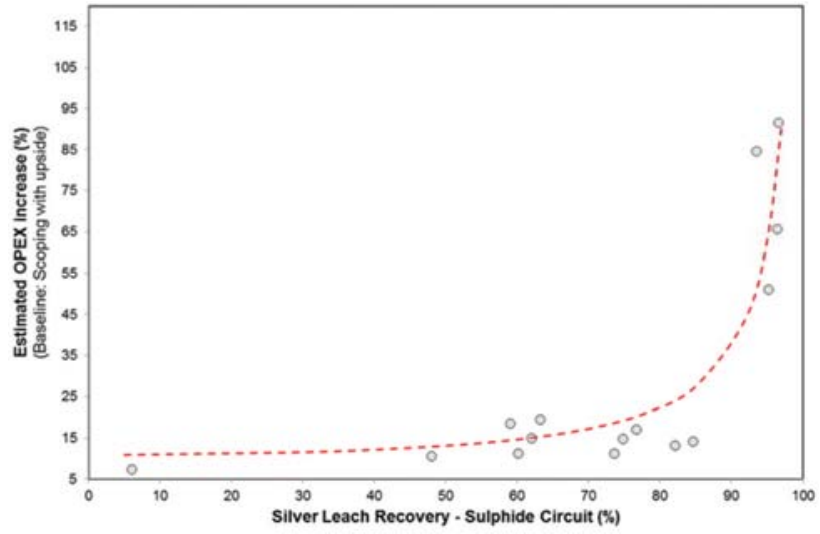

Figure 6-Relationship between OPEX increase and increasing silver recoveries

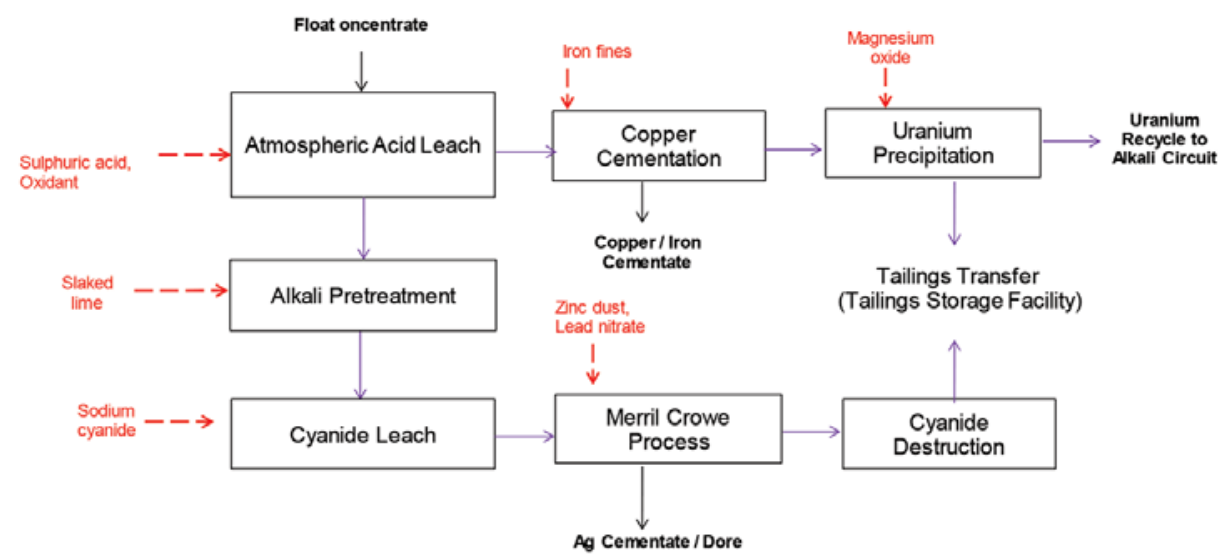

Figure 7-Block flow diagram for concentrate processing

amenable to direct cyanide leaching and silver recovery. The refractory silver species is thought to be an argento-jarosite compound, since the leachability improved with the addition of sodium compounds to the leach; this was probably due to the preferential formation of a sodium jarosite phase.

Furthermore, it was found that the possible argento-jarosite phase can be destroyed by incorporating an alkali pretreatment unit operation before cyanide leaching. The subsequent silver recovery was found to be dependent on the targeted $\mathrm{pH}$ of the alkali pretreatment unit operation. This in turn impacted on the alkali consumption of the pretreatment step. It was, therefore, concluded that a silver recovery of between $75 \%$ and $85 \%$ should be targeted as higher recoveries became value-destructive due to the increase in alkali consumption. The deposit has changed ownership a few times over the last couple of years, and it is suggested that the next level of engineering study be conducted should the uranium price and outlook improve.

\section{Acknowledgements}

This article is published with the permission of the deposit owner and DRA Projects. The authors would like to thank the DRA process team for their valuable input and peer reviewing of the article. The majority of the test work was conducted at ANSTO Minerals, with some test work also executed by MetCon, SGS Perth, and SGS South Africa.

\section{References}

FEASBY, D.G. 1980. Eldorado's Beaverlodge Operation. Canadian Mining Journal, June 1980. pp. 75-149.

Frost, R.L., Wills, R.A., Weier, M.L., and Martens, W. 2005. Thermal decomposition of synthetic argentojarosite Implications for silve production in medieval times. Thermochimica Acta, vol. 437, no. 1-2. pp. 30-33.

IAEA. 2001. Manual of acid in situ leach uranium mining technology. IAEATECDOC-1239. International Atomic Energy Agency, Vienna, Austria. August 2001,

Kasaini, H., Kasongo, K., Naude, N., and Katabua, J. 2008. Enhanced leachability of gold and silver in cyanide media: Effect of alkaline pretreatment of jarosite minerals. Minerals Engineering, vol. 21, no. 15. pp. 1075-1082.

LunT, D., Boshoff, P., BoyletT, M., and El-Ansary, Z. 2007. Uranium extraction: the key process drivers. Journal of the Southern African Institute of Mining and Metallurgy, vol. 107. pp. 419-426.

MERRITT, R.C. 1971. The Extractive Metallurgy of Uranium: Processing Operations. Colorado School of Mines Research.

Peacock, M., McDougall, S., Boshoff P., Butcher D., Ford M., Donegan S., and Bukunkwe D. 2016. Paladin Energy Ltd - Nano-filtration technology for reagent recovery. Proceedings of ALTA 2016 Uranium-REE Proceedings. ALTA Metallurgical Services, Melbourne, Australia. pp. 264-274. 